\title{
Geometrical Deposits on Microstructured Surfaces
}

\author{
Veronika Kubyshkina $^{1}$, Daniel Orejon ${ }^{1}$, Coinneach Mackenzie Dover ${ }^{1,2}$, Khellil Sefiane ${ }^{1,3^{*}}$ \\ 1. University of Edinburgh, School of Engineering, Kings Buildings, Mayfield Road, Edinburgh, EH9 3JL, UK \\ 2. Oden Institute for Computational Engineering and Sciences, The University of Texas at Austin, Texas TX 78712, USA \\ 3. Tianjin Key Lab of Refrigeration Technology, Tianjin University of Commerce, Tianjin 300134, China
}

\begin{abstract}
Research into evaporating droplets on patterned surfaces has grown exponentially, since the capacity to control droplet morphology has proven to have significant technological utility in emerging areas of fundamental research and industrial applications. Here, we incorporate two interest domains - complex wetting patterns of droplets on structured surfaces and the ubiquitous coffee-ring phenomenon of nanofluids containing dispersed aluminium oxide particles. We lay out the surface design criteria by quantifying the effect of pillar density and shape on the wetting footprint of droplets, yielding complex polygon droplet geometries. Our work is not constrained to pure liquids only, as we delve into the shape selection of particle-laden droplets of different concentrations. We visualise the deposition patterns through microscopy on surfaces exhibiting different features and further establish the ordering of particles on microscale surface asperities. At a high nanofluid concentration, we observe intriguing self-assembly of particles into highly ordered intricate structures. The collective findings of this work have the potential to enhance many industrial technologies, particularly attractive for high performance optical and electrical devices.
\end{abstract}

Keywords: geometrical wetting, tuneable surface topography, nanosuspensions, deposition patterns, particle assembly Copyright $(C$ The author(s) 2020.

\section{Introduction}

The physical understanding of microscale droplet dynamics has changed the paradigm of many scientific endeavours, due to the growing number of diverse applications, including inkjet printing, polymer-based LED displays, bio-microarrays, and so forth ${ }^{[1-3]}$. Specifically, the increasing ability to engineer surfaces with bespoke topographical and chemical features has been instrumental in studying the intricacies of the wetting phenomenon, leading to enhanced control over the solid-liquid interactions. Modifying surface characteristics has a profound effect on droplet behaviour, distinguished between scenarios ranging from complete liquid spreading and wetting on hydrophilic structured surfaces, to the formation of pearl drops in a non-wetting situation on hydrophobic (and superhydrophobic) textured surfaces - each state desirable for applications in diverse domains $^{[4-10]}$. The vast possibilities offered by tuneable surface characteristics has stimulated considerable research activity to expand droplet manipulation capabilities, with many studies turning to nature for inspiration due to the complex and hierarchical structuring characteristics of living organisms ${ }^{[11-14]}$. By integrating physics at the microscale with engineered surfaces, new methods have emerged for manipulating and controlling the solid-liquid interactions.

Notably, anisotropic surface texturing shows great potential for sophisticated directional wettability and adhesion $^{[15-17]}$. Anisotropic non-wetting behaviour includes directional droplet transportation and roll-off of droplets from surfaces ${ }^{[18-20]}$. Li et al. briefly examined the anisotropic footprints of water droplets, demonstrating the transition of wetting shapes by adjusting topological surface features ${ }^{[21]}$. Asymmetrical droplet spreading and imbibition, through surface anisotropy, has also been studied extensively. Water droplets with 3 , 4 and 6-fold symmetry have resulted from the anisotropy effect of the lattice arrangement of surface microstructures and their respective geometrical parameters ${ }^{[22]}$.

A significant technological utility of liquid-solid behaviour on textured surfaces lies in the ability to precisely regulate the wetting profile of droplets to create non-spherical geometries, for example, for

\footnotetext{
*Corresponding author: Khellil Sefiane

E-mail: k.sefiane@ed.ac.uk
} 
high-resolution liquid-based printing applications such as DNA sequencing and metal printing ${ }^{[23,24]}$. Desired droplet wetting geometries are primarily generated by altering the surface properties through topographical or chemical heterogeneities, manifesting a variety of polygon shapes for both sessile droplets and liquid films. Raj et al., for example, induced square, rectangular, hexagonal, octagonal and dodecagonal droplet footprints, specifically by tailoring the pillar density ${ }^{[25]}$. Later, using these experimental findings, Kumar and Raj simulated the evolution of the droplet periphery, demonstrating the polygon to square droplet transition, achieved by contact line zipping ${ }^{[26]}$. On the other hand, Courbin et al. harnessed the imbibition behaviour of several liquid mixtures, obtaining various polygonal shapes of thin-liquid films ${ }^{[27,28]}$. Recent studies have focused on enriching droplet profile selection by expanding the research to include complex droplet compositions, i.e. liquid mixtures, saline solutions and suspensions. Feng et al. found that the wetting area can also be controlled by manipulating the water-ethanol ratio on substrates with micropyramid cavities ${ }^{[29]}$. An increase in ethanol concentration induced the droplet wetting area to evolve from an octagon to a square. Saline droplets have also been investigated by varying the concentration of potassium chloride $(\mathrm{KCl})$ in water ${ }^{[30]}$. The wetting interface evolved from an octagon to a deformed rectangle with increasing salt concentration on micropyramid patterned surfaces. Interestingly, compared with the study of ethanol droplets done by Feng et al., both $\mathrm{KCl}$ and ethanol produced the same effect on the shape of droplets, despite the different effect that these solutions have on surface tension. The study of droplet profile as a function of surfactant concentration on textured surfaces showed different wetting transitions of evaporating droplets, corresponding to the initial surfactant concentration $^{[31,32]}$. The transition of droplet profile from octagon to square, and from square to rectangle, was observed during the drying process. Additionally, the ability to maintain a uniform droplet profile throughout the whole evaporation process was achieved for octagonal droplets $^{[31,32]}$. The findings unanimously demonstrate that surface chemistry and topography, as well as the intrinsic contact angle of the fluid, govern the wetting dynamics and droplet shape.
Although the specifics of surface chemistry and topography determining droplet wetting shape have been mostly understood, particle deposition patterns of non-spherical drops are, as of yet, largely unexplored. It bears limitations in many promising applications where the capacity to reliably create well-defined particulate deposits is of vital importance for pattern-particle assembly, for example, in high-performance optical devices and sensors ${ }^{[33,34]}$. However, creating high-quality patterns with predefined, distinct shapes has been challenging due to the coffee-ring effect, wherein particulates deposit in a ring-like manner ${ }^{[35]}$. Substantial research capability has been dedicated to predicting and controlling the spatial distribution of particle deposits in evaporating droplets, both reliably and efficiently. The rich morphologies of the drying patterns are intrinsically interlinked with parameters such as particle concentration, particle size, solvent composition and surface characteristics $^{[36-39]}$. Several studies have succeeded in producing uniform deposits by manipulating the shape of particulates ${ }^{[40,41]}$. Choi et al. used the coffee ring effect to their advantage to produce $3 \mathrm{D}$ microand nanoparticle patterns using evaporation-driven self-assembly ${ }^{[42]}$. Control over nanoparticle deposition patterns has also been realized by creating low-adhesion superhydrophobic substrates, exhibiting a range of shapes and sizes of superhydrophilic regions, thus creating deposit shapes including triangles, rectangles and ellipses ${ }^{[43]}$. Sáenz et al. incorporated both experimental and theoretical methods to study evaporation kinetics and deposition patterns of non-spherical drops ${ }^{[44]}$. They concluded that particles segregate to regions of higher curvature at the contact line, thus resulting in non-uniform deposition patterns at the droplet periphery. Another interesting study harnessed bacteria-containing droplets to examine the spatial distribution of deposits on micropatterned substrates, in relation to the shape profile of dried droplets ${ }^{[45]}$. More recently, Park et al. have demonstrated the ability to create hexagonal deposits on circular micropillars using colloidal suspensions of microsized particles ${ }^{[46]}$. Despite the growing interest in this field, there is still insufficient understanding pertaining to factors influencing the complex drying patterns of droplets containing dispersed material - in particular, the combined effect of several 
variables can provide detailed insights into the spatial arrangement of components. For example, by capitalising on the highly sophisticated surface fabrication techniques, bespoke environment combinations can be created for identifying and controlling particle ordering within surface structures. Although modifications of surface chemistry and topography have received some attention, the focus has been on exploiting rudimentary surface patterning or wettability ${ }^{[46-51]}$. However, for pure liquid droplets, flow patterns are also influenced by the shape of surface asperities (i.e. the sharp edge effect $)^{[52-55]}$. We could hence expect this surface parameter to manoeuvre the transport of suspended particles in solutions, adding to the existing database of the possible deposition patterns of particle-laden droplets.

Motivated by the current need to improve the resolution and operability of particle deposition patterns, we integrate two emerging fields by studying the drying patterns of particle-laden droplets with complex wetting morphologies. To meet this challenge, we investigate the wetting footprints of pure liquids, as well as aluminium oxide nanofluids of different concentrations. By combining fluid composition and surface patterning, we demonstrate the ability to create well-defined droplet shapes and maintain the desired profile for the entirety of the drying process. Attention is also dedicated to the role of surface topography on shape selection of droplets, namely, the population density of the array and the shape of the micropillars. We further evaluate the specifics of surface design in relation to the deposition patterns left by evaporated $\mathrm{Al}_{2} \mathrm{O}_{3}$ nanofluid droplets. Finally, we take a closer look at the localised deposition environment at the microscale, and establish the distribution of particles on the surface microstructures, by visualising the assembly of nanoparticles at the contact line as well as the droplet's interior upon complete evaporation. At its current stage, the aforementioned understanding is currently lacking, but through appropriate functionalisation can contribute to the advancement of biotechnology, optoelectronics, tissue engineering, cell biology, high-throughput drug discovery and low-cost point-of-care devices ${ }^{[56-61]}$.

\section{Materials and methods}

The initial examination involved pure liquid drop- lets comprised of distilled water, followed by analytical reagent grade ethanol (Fisher Scientific). To assess the drying-mediated patterns, nanofluid suspensions were prepared using ethanol as the base liquid, and aluminium oxide nanopowder, $\mathrm{Al}_{2} \mathrm{O}_{3}$, with a particle size of $c a$. $50 \mathrm{~nm}$ (Sigma Aldrich), with concentrations of $0.01 \mathrm{wt} \%$, $0.05 \mathrm{wt} \%$ and $0.1 \mathrm{wt} \% \mathrm{Al}_{2} \mathrm{O}_{3}$. The resulting nanoparticle liquid suspensions were sonicated for $2 \mathrm{~h}$ initially, and for 30 min prior to each subsequent use to ensure thorough dispersion. Silicon substrates were decorated with various micropillar geometries, arranged in a square lattice and coated in hydrophobic perfluorodecyltrichlorosilane (FDTS) through vapour deposition. The substrates were fabricated using photolithography and Deep Reactive Ion Etching (DRIE) techniques in the Scottish Microelectronics Centre at the University of Edinburgh $^{[62]}$. On smooth FDTS coated surfaces, the intrinsic contact angle for water is $112^{\circ}$, whilst the corresponding value for ethanol is $60^{\circ}$. The geometric parameters of the micropillars are characterized by the shape, height $(h)$, lateral dimensions $(d)$ and edge-to-edge spacing $(s)$ (Fig. 1a). Whilst the height and the lateral dimensions of the pillars were kept constant $(h=10 \mu \mathrm{m} \pm 2 \mu \mathrm{m}$ and $d=10 \mu \mathrm{m}$ ), the shape and the spacing were varied, giving a total of 16 surface configurations. The different micropillar shapes are visualised in Fig. 1b: circular, square, star-shaped (6-point) and triangular pillars. The spacing $(s)$ was varied for all pillar geometries $(5 \mu \mathrm{m}$, $10 \mu \mathrm{m}, 20 \mu \mathrm{m}$ and $40 \mu \mathrm{m}$ ), which allowed for systematic control of surface wettability. The surfaces were cleaned prior to use with distilled water and dried using compressed nitrogen to remove any particulates.

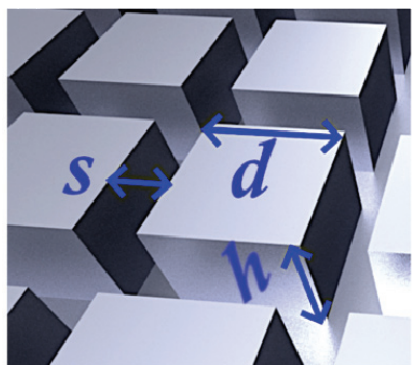

(a)

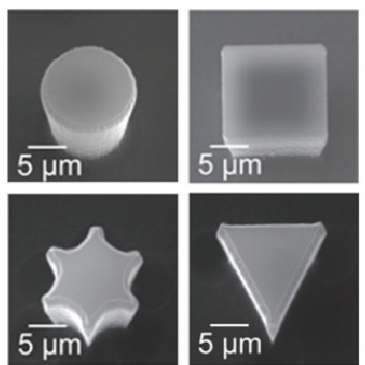

(b)
Fig. 1 (a) Schematic of an array of square pillars, with defined microscale pillar geometries. (b) Scanning Electron Microscope (SEM) images of the micropillar islands, showing the different pillar geometries: circles, squares, stars and triangles. Scale bar is $5 \mu \mathrm{m}$. 
Droplets, of the same initial volume of $5 \mu \mathrm{L}$, were manually deposited on the microstructured substrates using a glass microsyringe (Hamilton). The wetting profile of droplets was visualised through a top-down optical inspection camera (xiQ MQ013CG-ON, Ximea, Germany) with a Nikon $105 \mathrm{~mm}$ f/2.8 lens (AF Micro Nikkor, Nikon, Japan). Droplets were illuminated by an LCD cold light source (KL 1500, Schott, Germany). The experiments were carried out at ambient conditions $\left(21{ }^{\circ} \mathrm{C} \pm 2{ }^{\circ} \mathrm{C}, 46 \% \pm 10 \%\right.$ relative humidity, and atmospheric pressure) and repeated at least three times for each liquid/surface configuration. Further visualisation of the nanoparticle deposits left on the substrate after complete evaporation was conducted using an inspection microscope (DM12000 M, Leica Microsystems, Germany). The microscope was adjusted to capture the profile of the wetting area deposits, in addition to focusing on the local, microscale morphology of $\mathrm{Al}_{2} \mathrm{O}_{3}$ deposits at the contact line and droplet centre. Deposit distribution was captured both at the top of the pillars (i.e. the roughness level), as well as the in the space between the pillars (i.e. base level).

\section{Results and discussion}

\subsection{Droplet wetting profile}

We examine the wetting profile of pure liquids and particle-laden suspensions on textured surfaces, exhibiting diverse geometrical parameters. Emphasis is placed on the sensitivity of the initial wetting interface to changes in surface topography, specifically, the shape of the pillars and the pillar-to-pillar distance. Fig. 2 demonstrates the droplet footprint of pure liquids (water and ethanol) on surfaces with different post geometries (circular, square, star-shaped and triangular) and increasing pillar spacing $(5 \mu \mathrm{m}, 10 \mu \mathrm{m}, 20 \mu \mathrm{m}$ and $40 \mu \mathrm{m})$. For all surface configurations, pure water droplets profile conformed to a spherical cap (Fig. 2a), ascribed to the coupling effect of the high surface tension of the liquid, and the large solid-liquid interfacial tension due to the intrinsic hydrophobicity of the surface, consistent with Ref. [63]. However, upon deposition of low surface tension fluids, (i.e. more wetting liquids), in this case ethanol, droplets are subject to significant deformations in morphology, as depicted in Fig. $2 b$, realising a variety of wetting configurations.
Upon closer inspection of Fig. 2b, we see that for a high pillar spacing $(s=40 \mu \mathrm{m})$, the contact line profile is akin to a typical spherical cap. In the case of symmetric pillar shapes - circular, square and 6-point star - reduction in the pillar spacing incited a polygonal configuration of the droplet's periphery ( $s=10 \mu \mathrm{m}$ and $20 \mu \mathrm{m})$, and a largely square profile on substrates with the smallest pillar spacing $(s=5 \mu \mathrm{m})$. This behaviour is consistent with observations by Raj et al., who report a transformation of the droplet wetting area with increasing pillar density from an octagon to a square ${ }^{[25]}$. In a different manner, triangular micropillars give rise to an irregular polygonal shape with a loss of the contact line's axial symmetry. Here, the droplet's anterior resembles a triangle along the direction of the pillars on when $s=10 \mu \mathrm{m}$ and $20 \mu \mathrm{m}$, while an elongated rectangular shape was observed for $s=5 \mu \mathrm{m}$. This is attributed to the uni-directional liquid spreading by virtue of the anisotropy of triangular pillars retarding the flow through their blunt ends ${ }^{[15,52,53]}$. Significant deviation from a circular contact line profile, i.e., spherical cap, resulted on densely populated microstructured surfaces, whereas increasing the pillar spacing ensued a more circular periphery.

On the basis thereof, pillar-to-pillar spacing (i.e. surface roughness) produced the most emphatic effect on the contact line profile, whilst more subtle geometrical differences of the droplet's morphology were realised based on pillar shape. The diversity of the profiles observed when depositing these drops on patterned surfaces raises questions about the effect on the subsequent evaporation dynamics. As previous studies have demonstrated, the evaporation of non-symmetrical drops depends on the local azimuthal curvature of the interface ${ }^{[44]}$. Therefore, a higher evaporation rate is expected where the curvature is highest. Sharp corners of droplets, as shown in Fig. 2, will exhibit regions of higher evaporation than a flat interface. This leads to an interesting conclusion on how pillar shape and spacing on patterned surfaces can be harnessed to control the local evaporation rate of sessile drops. Furthermore, in the case of nano-suspension droplets, the deposits following local dry-out can also be controlled using distinct surface patterns. Thus, the described initial wetting configuration of pure droplets provides a foundation for 
(a)

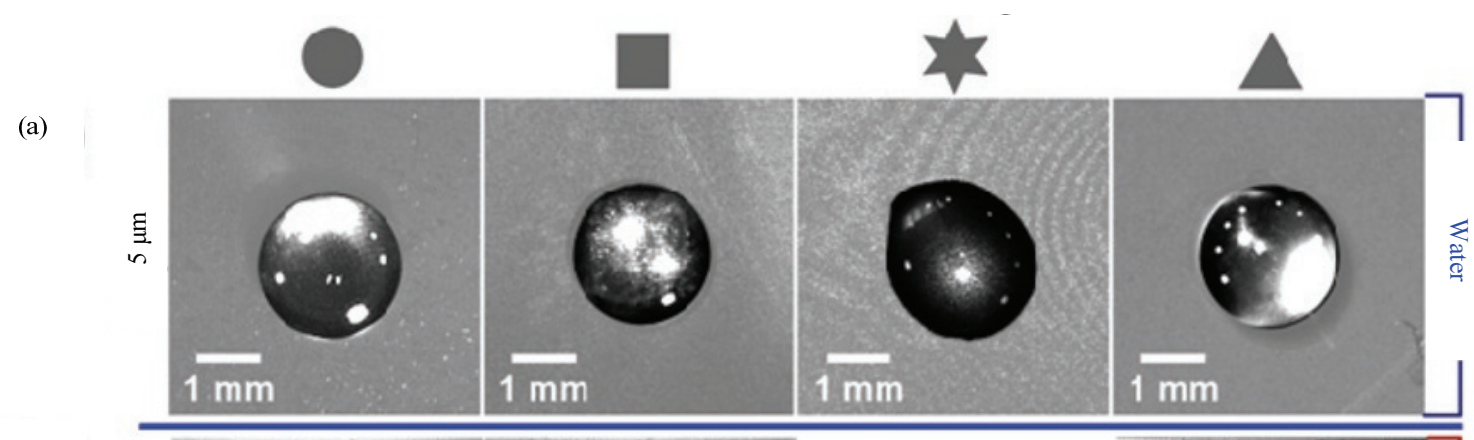

(b)

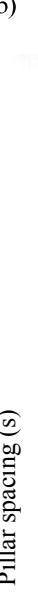
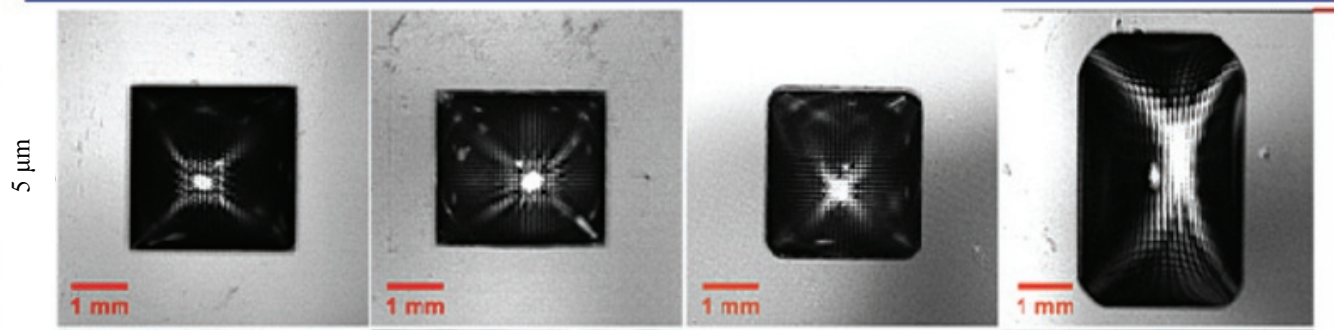

0
0
0
0
0
0
0
0
0
0
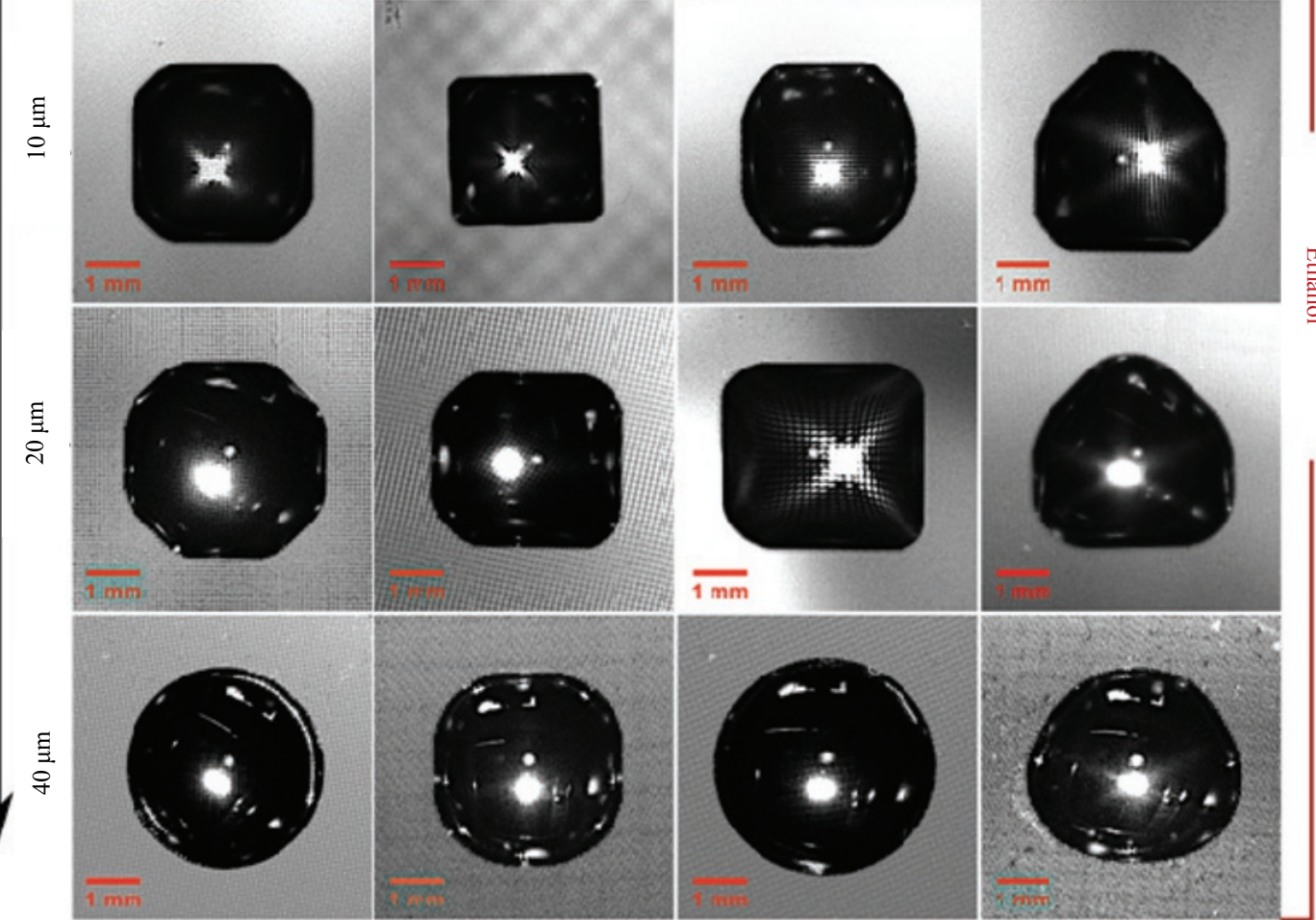

Fig. 2 Top-down visualisation of the initial droplet wetting profile for pure fluids on substrates with circular, square, star-shaped and triangular pillars (left to right). Scale bar is $1 \mathrm{~mm}$. (a) Pure water droplets on substrates with different pillar geometries, all with a spacing of $5 \mu \mathrm{m}$. (b) Pure ethanol droplets on substrates with different pillar geometries and increasing pillar spacing $(s=5 \mu \mathrm{m}, 10 \mu \mathrm{m}, 20 \mu \mathrm{m}$, $40 \mu \mathrm{m})$.

examining the behaviour of complex fluids, under the same experimental conditions.

Thereupon, the central interest lies in the morphology of nanofluid suspensions containing aluminium oxide nanoparticles dispersed in ethanol with three dif- ferent concentrations $(0.01 \mathrm{wt} \%, 0.05 \mathrm{wt} \%$ and $0.1 \mathrm{wt} \% \mathrm{Al}_{2} \mathrm{O}_{3}$ ). The resulting droplet profiles, corresponding to the highest nanofluid concentration $(0.1 \mathrm{wt} \%)$ are depicted in Fig. 3. We focus on the extreme case - the highest concentration of $\mathrm{Al}_{2} \mathrm{O}_{3}-$ to determine the 


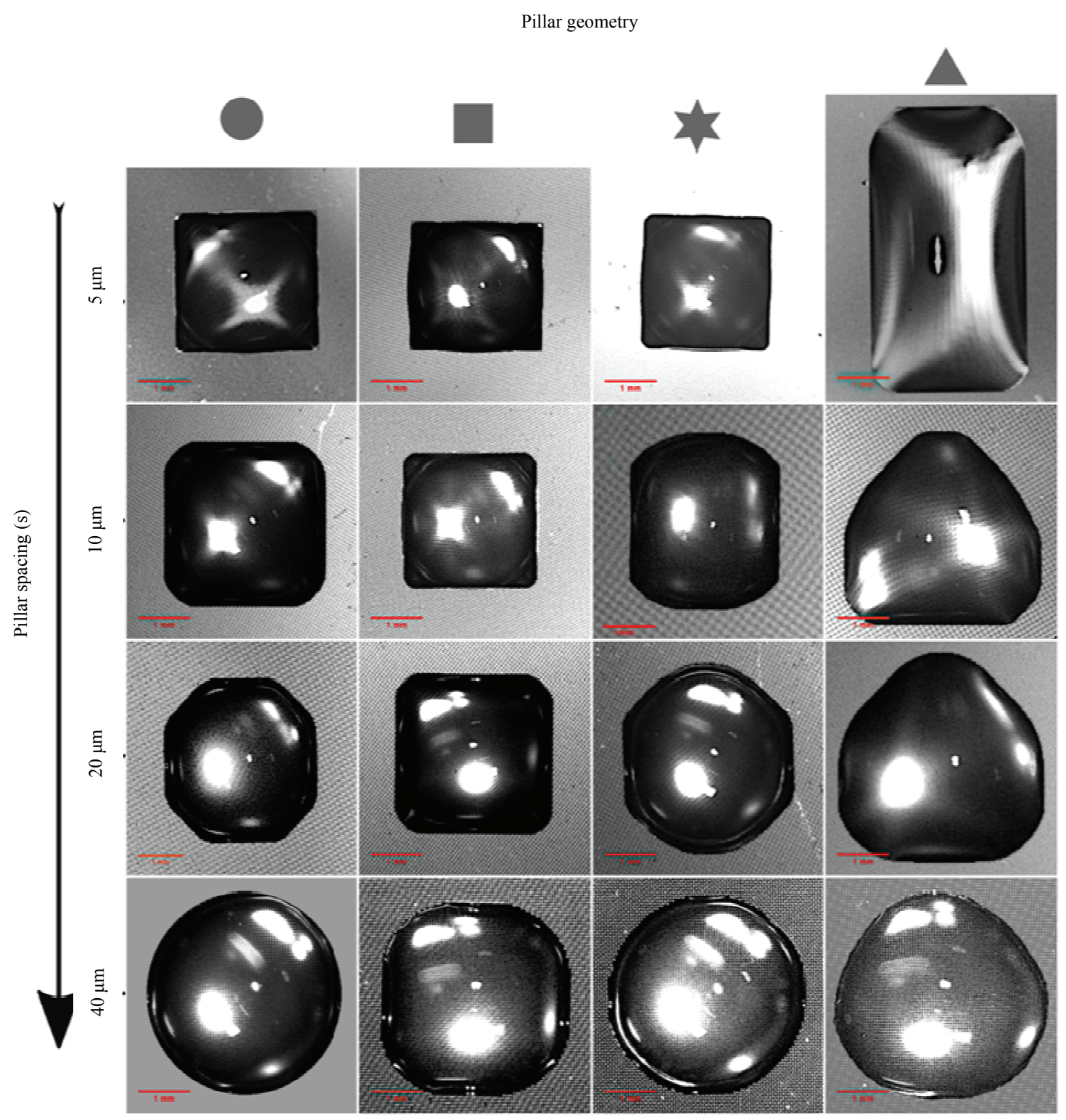

Fig. 3 Top-down visualisation of the initial wetting profile for $0.1 \mathrm{wt} \% \mathrm{Al}_{2} \mathrm{O}_{3}$ nanofluid droplets on substrates with circular, square, star-shaped and triangular pillars (left to right), and increasing pillar spacing ( $s=5 \mu \mathrm{m}, 10 \mu \mathrm{m}, 20 \mu \mathrm{m}, 40 \mu \mathrm{m})$. Scale bar is $1 \mathrm{~mm}$.

role of nanoparticles on droplet shape selection. Comparison of pure ethanol and nanofluid droplet wetting shape (i.e. Figs. $2 \mathrm{~b}$ and Fig. 3), indicates that the addition of nanoparticles does not distort the droplet profile established for pure ethanol. This, perhaps, is due to the inconsequential effect of aluminium oxide on the surface tension of droplets (less than $1 \%$ and $2 \%$ differences in the surface tension of water have been reported, when compared to $50 \mathrm{~nm} \quad \mathrm{Al}_{2} \mathrm{O}_{3}$-water $(0.2 \%)$ and $\mathrm{Al}_{2} \mathrm{O}_{3}$-ethanol (0.2\%) nanofluids respectively), unlike the pronounced difference between pure water and ethanol (Figs. 2a and 2b) ${ }^{[38,64]}$. For all pillar shapes, a distinct correlation can be gleaned from Fig. 3, similar to that reported earlier in Fig. $2 b-$ as the pillar density increases (i.e. decreasing pillar spacing), the wetting area evolves from a largely square geometry (with sharp corners) to a circular profile, only weakly perturbed by the microstructures. Pillar shape contributes to droplet shape selection also, with triangular pillars inducing the biggest change in shape, causing the contact line to conform to the direction of the blunt micropillar edges (i.e. the sides of triangles). Variations of polygon shapes 
are attained for intermediated pillar spacings $(10 \mu \mathrm{m}$ and $20 \mu \mathrm{m})$, irrespective of pillar geometry, whilst more circular shapes are reported for substrates with $40 \mu \mathrm{m}$ pillar spacing.

A quantitative analysis of the contact line morphology, which reflects the geometric shape properties of the droplets, is presented next. Top-down visualisation of the initial droplet morphology, as seen in Fig. 3, highlights several interesting observations. For example, it stands to reason that for square and circular pillars, regardless of pillar spacing and hence droplet profile, the aspect ratio between the major axis width $(W)$ and length $(L)$ of the droplet's wetting area is close to unity (Table 1). On the other hand, the symmetry of the wetting profile is disrupted for droplets on triangular and star-shaped pillars. To quantify the deviation from the typical spherical cap geometry, the circularity $(C)$ of the initial shape of droplets is determined. In other words, we characterise the observed droplet profiles by analysing the departure from roundness, with $C=1$ for a perfect circle. By making use of ImageJ, the circularity (C) of the droplets is extracted - included in Table 1. As expected, the circularity values tend to 1 as the pillar density decreases, i.e., conforming to a spherical droplet profile, whilst tightly packed microstructures yield deviations from circularity as high as $30 \%$. Both width and length of the wetting area, as well as the droplet's circularity, are in quantitative agreement with the experimental observations in Fig. 3.

To further detail the diversity of the observed wetted profiles, a closer examination of the deposits left by evaporated droplets at the contact line is warranted. A microscopic view of the droplet periphery at the convex corners for a $0.1 \mathrm{wt} \%$ concentration nanofluid is exemplified in Fig. 4, across three different surface configurations. Microscopy findings confirm the presence of the zipping-wetting mechanism, responsible for the formation of non-spherical wetting footprints ${ }^{[25-27]}$. When comparing surfaces decorated with circular (Fig. 4a) and triangular (Fig. 4b) pillars, of note are the differences in the length of the deposit lines in the orthogonal and diagonal directions. The elongated profile of droplets on triangular pillars corresponds with the increased pinning length along the diagonal, instigated by the rapid and uninhibited propagation of liquid between the posts. These findings are in consonance with the simulation analysis on triangular pillars by Blow et al., presenting an extensive overview of the imbibition and pinning dynamics leading to anisotropic droplet behaviour ${ }^{[52,53]}$.

Of significance, also, is the capacity of the droplet to retain its initial profile, independent of the wetting morphology, for the entirety of the drying process. This observed experimental behaviour relates to the pinning phenomena of $\mathrm{Al}_{2} \mathrm{O}_{3}$ nanofluid droplets, whereby, irrespective of evaporation, the base of the droplet remains unaltered. In line with previous studies, the addition of nanoparticles enhances the pinning effect at the contact line, with $0.05 \mathrm{wt} \%$ and $0.1 \mathrm{wt} \% \mathrm{Al}_{2} \mathrm{O}_{3}$ droplets maintaining a constant contact radius throughout evaporation $^{[65]}$. At the lowest concentration $(0.01 \mathrm{wt} \%)$, droplet depinning was witnessed at $40 \mu \mathrm{m}$ pillar spacing only (i.e. spherical droplets). For reference, pure ethanol depins on substrates with both $20 \mu \mathrm{m}$ and $40 \mu \mathrm{m}$ spacing.

\subsection{Nanoparticle deposits}

\subsubsection{Surface topography on deposition patterns}

The overall deposition morphology of dried $\mathrm{Al}_{2} \mathrm{O}_{3}$ nanofluid droplets is characterized on surfaces range of wetting characteristics and pillar geometries. We observe different deposition patterns, predicated on both surface structure and concentration of dispersed

Table 1 Summary of the major axis width $(W)$, length $(L)$ and circularity $(C)$ of the droplet's initial wetting profile for 0.1 wt $\% \mathrm{Al}_{2} \mathrm{O}_{3}$ nanofluid on substrates with circular, square, star-shaped and triangular pillars and increasing pillar spacing. The values correspond to the droplets in Fig. 3.

\begin{tabular}{|c|c|c|c|c|c|c|c|c|c|c|c|c|}
\hline \multirow{2}{*}{ Pillar spacing $(\mu \mathrm{m})$} & \multicolumn{3}{|c|}{ Circle } & \multicolumn{3}{|c|}{ Square } & \multicolumn{3}{|c|}{ Star } & \multicolumn{3}{|c|}{ Triangle } \\
\hline & $W(\mathrm{~mm})$ & $L(\mathrm{~mm})$ & $C(-)$ & $W(\mathrm{~mm})$ & $L(\mathrm{~mm})$ & $C(-)$ & $W(\mathrm{~mm})$ & $L(\mathrm{~mm})$ & $C(-)$ & $W(\mathrm{~mm})$ & $L(\mathrm{~mm})$ & $C(-)$ \\
\hline 5 & 2.71 & 2.65 & 0.763 & 2.49 & 2.40 & 0.756 & 2.48 & 2.52 & 0.795 & 2.95 & 5.34 & 0.794 \\
\hline 20 & 3.38 & 3.43 & 0.915 & 3.01 & 3.00 & 0.875 & 3.28 & 3.59 & 0.910 & 3.93 & 3.98 & 0.916 \\
\hline 40 & 3.75 & 3.85 & 0.978 & 3.61 & 3.66 & 0.930 & 3.75 & 3.75 & 0.983 & 4.05 & 3.89 & 0.951 \\
\hline
\end{tabular}



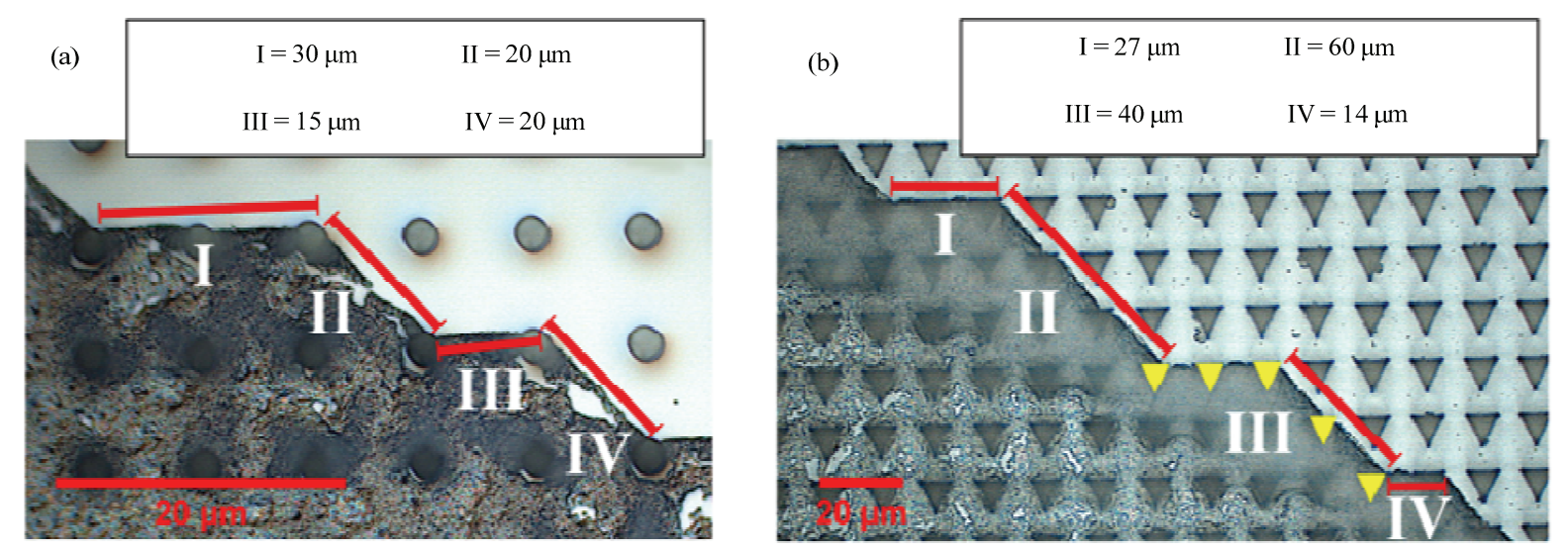

Fig. 4 Microscope images of the contact line corner, showing details of pinning for an evaporated droplet containing $0.1 \mathrm{wt} \% \mathrm{Al}_{2} \mathrm{O}_{3}$. Surface patterned with (a) circular pillars and (b) triangular pillars. The pillar spacing is $5 \mu \mathrm{m}$ for both. Scale bar is $20 \mu \mathrm{m}$.

particles in solution - a pronounced coffee-ring effect, irregular deposits and a comparatively uniform pattern. The presence of a single ring-like pattern, and the absence of additional ring structures within the centre of the deposits, is in accordance with the observed pinning of the droplets, maintained throughout the entirety of the drying process, as discussed in the previous section (i.e. constant contact radius mode).

In view of this, let us first examine the effect of particle concentration on the final deposition patterns following liquid drying. We would like to highlight here the resemblance of the overall deposition patterns in Fig. 5 to the droplet shapes reported in Fig. 3 for the different micropillar configurations. A number of studies have identified the significance of nanofluid composition by establishing a direct correlation between the concentration of solute and the ordering and thickness of deposits, generating diverse residual footprints for conventional droplet geometries ${ }^{[36,66-69]}$. We extend the current research to include drying patterns resulting from polygonal wetting areas for three concentrations of $\mathrm{Al}_{2} \mathrm{O}_{3}$ nanoparticles. For the lowest concentration $\left(0.01 \mathrm{wt} \% \mathrm{Al}_{2} \mathrm{O}_{3}\right)$, we see only a faint pattern on substrates with pillar spacing of $5 \mu \mathrm{m}, 10 \mu \mathrm{m}$ and $20 \mu \mathrm{m}$, with only a hint of ring-shaped contact line deposits (Fig. 5a). However, at a pillar-to-pillar distance of $40 \mu \mathrm{m}$, irregular deposits ensue due to the depinning of these droplets, where an inner concentrated deposit is witnessed upon drying. At the intermediate nanoparticle concentration $(0.05 \mathrm{wt} \%)$, on substrates with closely packed pillars $(s=5 \mu \mathrm{m}$ and $10 \mu \mathrm{m})$, a relatively irre- gular coffee-ring deposition pattern is achieved (Fig. 5b). The particle density at the droplet periphery is not homogeneous, and as such, is inconsistent with the classic coffee-ring pattern. For the case where $s=10 \mu \mathrm{m}$, the substantially lighter particle regions at the corners of the square are associated with the presence of corner films (as highlighted by the arrows in Fig. 5b), clearly correlating to the smaller localised volume compared to the bulk droplet. Contrarily, the coffee-ring effect becomes more salient with decreasing pillar density, i.e. increasing pillar spacing, $(s=20 \mu \mathrm{m}$ and $40 \mu \mathrm{m})$, and by extension with an increase in droplet circularity, leaving thick uniform deposits at the contact line (Fig. 5b). The deposition distribution at $0.05 \mathrm{wt} \%$ is attributed to the radial, outward capillary flow, replenishing the evaporated liquid, thus, ensuring the congregation of particles at the contact line ${ }^{[35]}$.

At the highest concentration $(0.1 \mathrm{wt} \%)$, the coffee-ring effect is still distinguishable, yet is significantly less pronounced than for $0.05 \mathrm{wt} \%$, such that particles accumulate both at the contact line and the interior of the droplet, albeit with different densities (Fig. 5c). Given that deposit thickness increases with concentration, the observed pattern for $0.05 \mathrm{wt} \%$ (Fig. $5 \mathrm{~b}$ ) would be expected to become more pronounced at $0.1 \mathrm{wt} \% \mathrm{Al}_{2} \mathrm{O}_{3}$, especially due to the stronger pinning effect at a higher concentration $^{[36,65]}$. On the contrary, the particle distribution is undoubtedly more uniform for the highest concentration, with a lower overall fraction of deposits located at the droplet's periphery, compared to the particle profile of the intermediate concentration 
(a)

$0.01 \mathrm{wt} \% \mathrm{Al}_{2} \mathrm{O}_{3}$

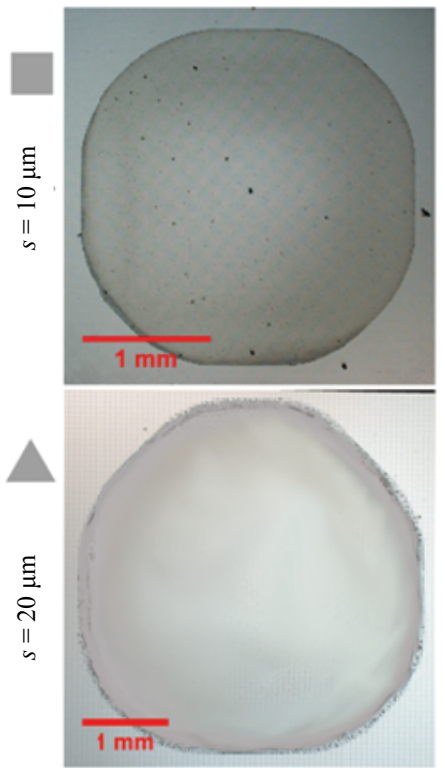

(b)

$0.05 \mathrm{wt} \% \mathrm{Al}_{2} \mathrm{O}_{3}$

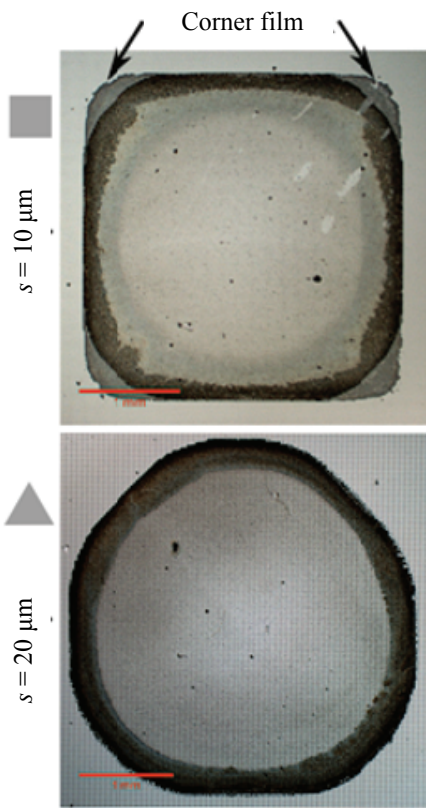

(c)

$0.10 \mathrm{wt} \% \mathrm{Al}_{2} \mathrm{O}_{3}$

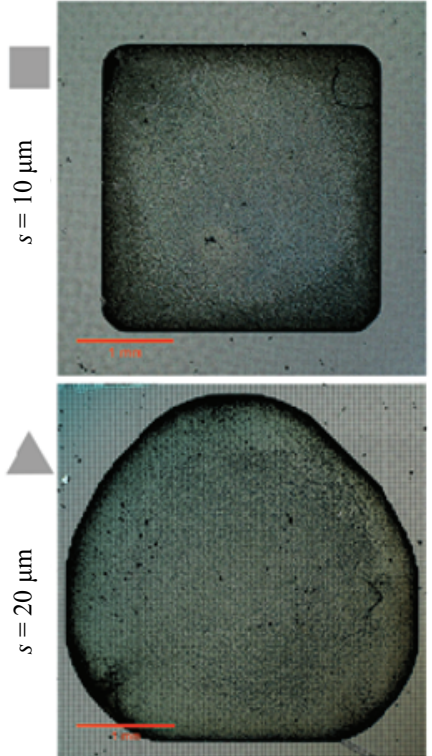

Fig. 5 Optical microscope images of the $\mathrm{Al}_{2} \mathrm{O}_{3}$ deposition patterns formed after droplet evaporation. (a) Lowest nanoparticle concentration $\left(0.01 \mathrm{wt} \% \mathrm{Al}_{2} \mathrm{O}_{3}\right)$; (b) intermediate nanoparticle concentration $\left(0.05 \mathrm{wt} \% \mathrm{Al}_{2} \mathrm{O}_{3}\right)$ and $(\mathrm{c})$ highest nanoparticle concentration $(0.1 \mathrm{wt} \%$ $\mathrm{Al}_{2} \mathrm{O}_{3}$ ) on substrates with square pillars, $10 \mu \mathrm{m}$ apart (top row) and triangular pillars, $20 \mu \mathrm{m}$ apart (bottom row). Scale bar is $1 \mathrm{~mm}$.

$(0.05 \mathrm{wt} \%)$. The boundary ring size is also visibly narrower. The effect can be explained by considering the particle-particle and particle-fluid interactions with respect to concentration. At a lower concentration, the particle-particle interaction is weak, such that the particle interaction with the fluid dominates, allowing deposits to form at the contact line through capillary outflow. However, at a high particle concentration, the particle-particle interaction strengthens and governs, partially restricting their movement towards the periphery ${ }^{[70-72]}$. Coupled with the fast evaporation of the solvent - i.e. ethanol - the particles do not have sufficient time to collectively assemble into a thick ring at the contact line. The presence of agglomerates at $0.1 \mathrm{wt} \%$ concentration - confirmed in the proceeding sections through microscopy - is in line with studies linking particle-particle interaction to changes in drying patterns ${ }^{[70,72,73]}$. Note though, the preferential accumulation of particles at the corners of square droplets, resulting from an increase in the local evaporation flux at these locations due to the large curvature of the contact line, is consistent with literatures ${ }^{[35,44]}$. Whilst the deposition patterns inside the domain are contingent on particle concentration, the overall morphology of the droplet boundary of $\mathrm{Al}_{2} \mathrm{O}_{3}$ nanofluids remains unchanged.

\subsubsection{Localised microscale deposition}

A closer inspection of the deposits left by evaporated drops helps to map out the localised distribution of $\mathrm{Al}_{2} \mathrm{O}_{3}$ nanoparticles on the surface microstructure level. With the aid of an optical microscope, we establish the particle density at the three-phase contact line and the centre of the droplet. Specifically, we draw attention to the distribution of nanoparticles on pillar islands, as well as in the space between the pillars - denoted as the roughness level and base level respectively (Fig. 6). The aforementioned results can tell us about the specifics of the flow within an evaporating particle-laden droplet. Several notable observations arise from looking at Fig. 6, depicting the particle deposition on a surface with square pillars, $5 \mu \mathrm{m}$ apart. For the lowest concentration ( $\left.0.01 \mathrm{wt} \% \mathrm{Al}_{2} \mathrm{O}_{3}\right)$, a high proportion of the particles were found on pillar tops at the contact line, with some deposits accumulating between the pillars also (Fig. 6a(i)). Whereas, at the droplet centre, we observed sparse deposits on pillar tops and no deposits between 


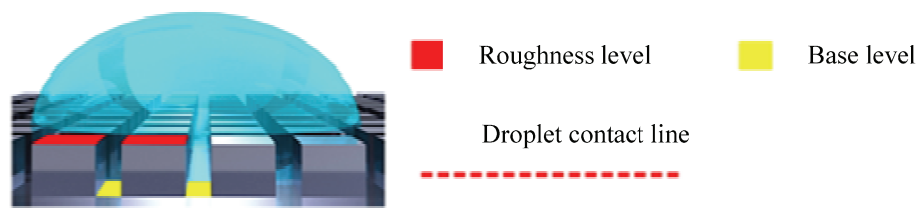

(a)

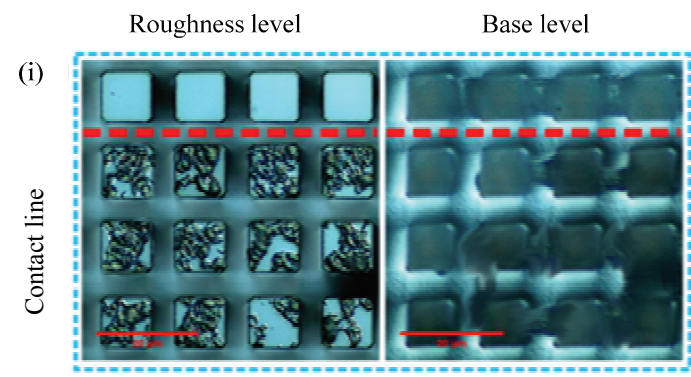

(ii)

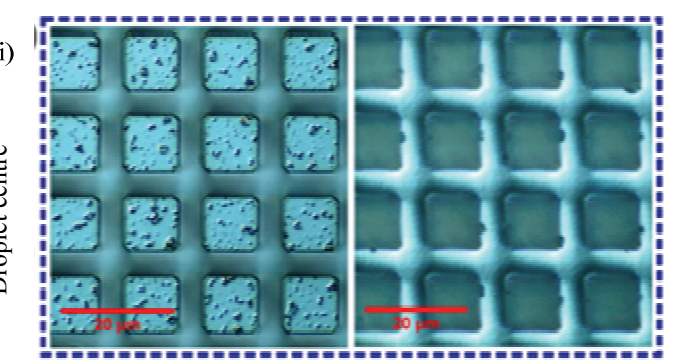

(b)

$0.10 w t \% \mathrm{Al}_{2} \mathrm{O}_{3}$

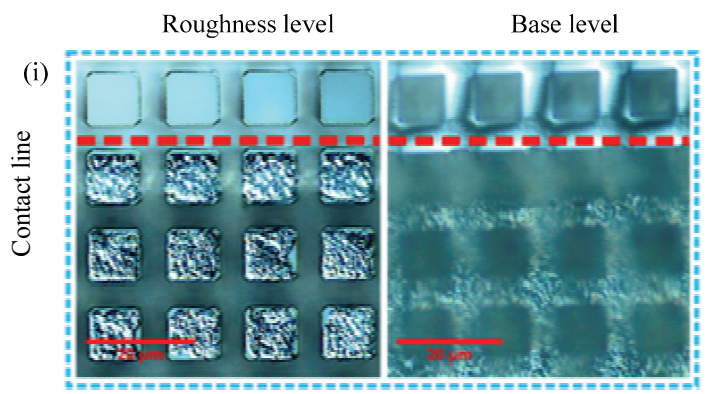

(ii)

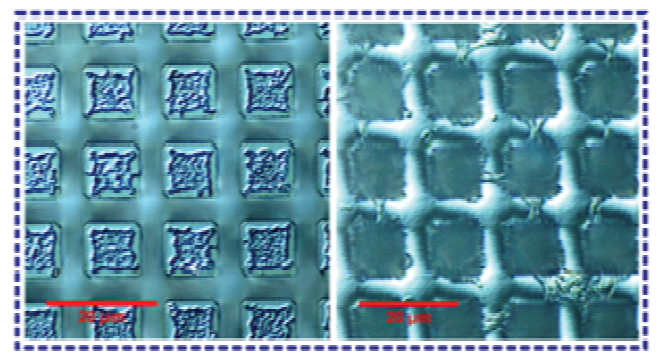

Fig. 6 Microscopy images of the localised deposition patterns at the contact line (i) and the centre of the droplet (ii) after evaporation of (a) $0.01 \mathrm{wt} \%$ and (b) $0.1 \mathrm{wt} \% \mathrm{Al}_{2} \mathrm{O}_{3}$. Roughness level corresponds to the top of the pillars and base level is the space between the pillars represented in the schematic (top left). The substrates are patterned with square pillars, $5 \mu \mathrm{m}$ apart. Scale bar is $20 \mu \mathrm{m}$.

pillars (Fig. 6a(ii)). Far from the contact line, the arrangement of residual deposits on pillar islands would imply the weak particle-particle interaction and the lack of particles between the structures is indicative of the dominant capillary flow at lower concentrations. Contrastingly, at the highest nanofluid concentration $\left(0.1 \mathrm{wt} \% \mathrm{Al}_{2} \mathrm{O}_{3}\right)$, we see agglomeration of nanoparticles at the droplet centre, with the pillar tops coated in a deposition pattern matching that of the pillar shape (in this case, square), albeit with a surrounding border (Fig. 6b(ii)). Between the pillars, nanoparticles self-assemble into branch-like formations, described in further depth in the proceeding section. At the contact line, the deposits are dense across all levels of the surface, with complete coverage of the available surface area (Fig. 6b(i)). This is to be expected, given the enhanced pinning effect and the strengthened particle-particle interaction at higher levels of nanoparticle concentration. The direct visualisation of particle ag- glomeration on the surface, namely, the settling on microstructures inside the droplet's domain, is in conjunction with our earlier discussion regarding the more uniform particle distribution, bounded by a thin ring, addressed in section 3.2.1. Thus, by amalgamating the macroscale observations of the previous section with the microscopic effects, a more comprehensive understanding of the particle transport towards the triple-phase contact line can be achieved. These findings have brought to light the self-assembly of nanoparticles at the highest concentration of $\mathrm{Al}_{2} \mathrm{O}_{3}$, which merits the following closer inspection.

\subsubsection{Nanoparticle self-assembly}

At the highest nanoparticle concentration $(0.1 \mathrm{wt} \%$ $\mathrm{Al}_{2} \mathrm{O}_{3}$ ), self-assembly of highly ordered and complex nanoparticle structures was observed between the pillars (Fig. 7), specifically in the area outwith the contact line. Fig. 7 highlights the intricate patterns formed on a 
(a)

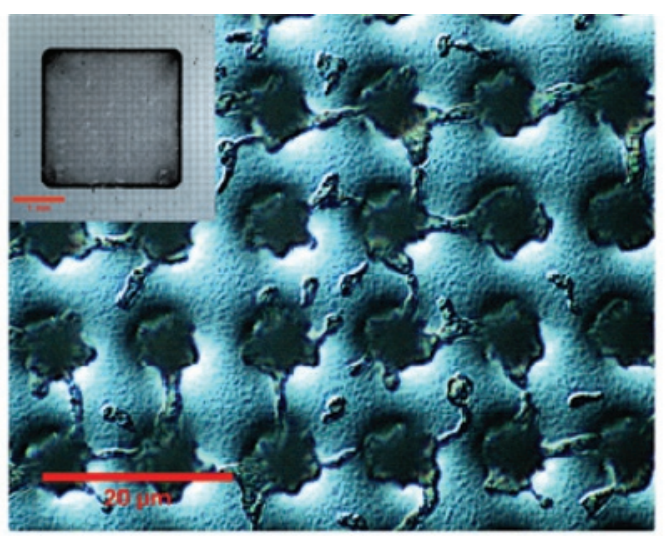

(c)

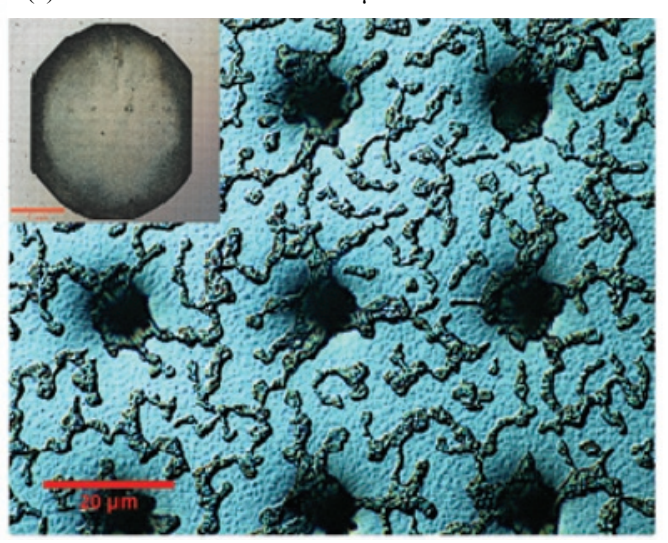

(b)

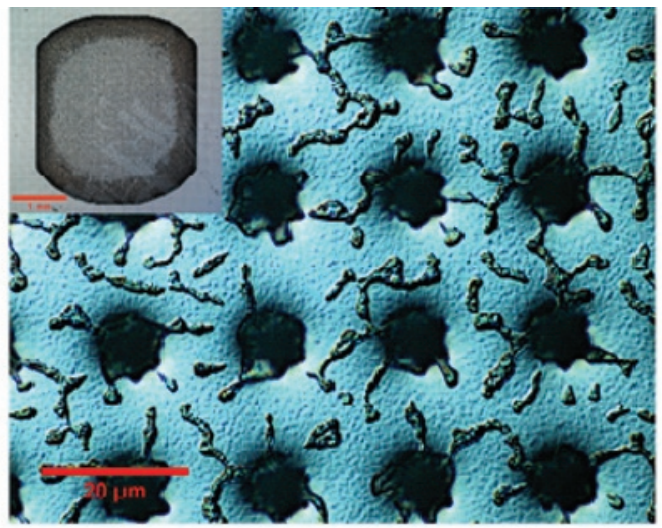

(d)

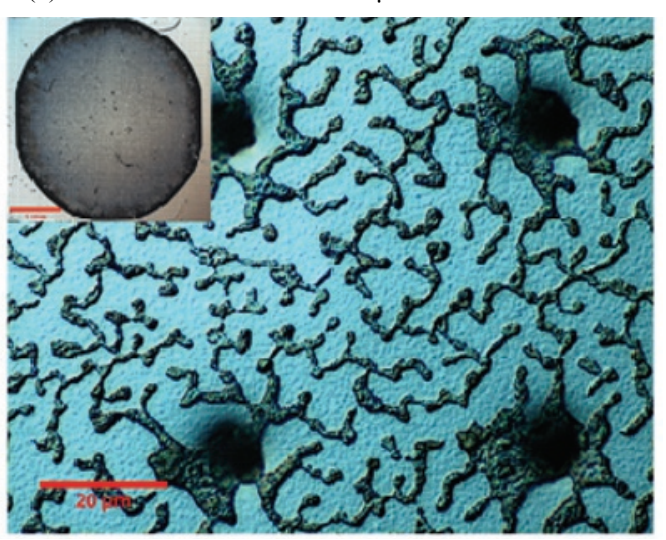

Fig. 7 Self-assembled particle morphologies of evaporated $0.1 \mathrm{wt} \% \mathrm{Al}_{2} \mathrm{O}_{3}$ nanofluid droplets, for a substrate with star-shaped pillars (6-point) and increasing pillar-to-pillar spacing. Microscope images for pillars with a spacing of (a) $5 \mu \mathrm{m}$, (b) $10 \mu \mathrm{m}$, (c) $20 \mu \mathrm{m}$ and (d) 40 $\mu \mathrm{m}$. The scale bar is $20 \mu \mathrm{m}$. The droplet shape and deposition footprint are shown in the inserts, all with a scale bar of $1 \mathrm{~mm}$.

surface decorated with star-shaped pillars and various pillar spacings. The branch-like structuring extends from the base of the pillars, increasing in complexity proportionally with the pillar spacing. The particle-fluid interactions of $\mathrm{Al}_{2} \mathrm{O}_{3}$ nanofluids have been found to increase with an increase in concentration, but only up to a critical concentration level ${ }^{[70]}$. Beyond this level, the particle-particle interactions dominate, resulting in the agglomeration and the associated nanoparticle self-assembly. A larger spacing between pillars seems to allow more interactions within the available space, forming longer and thicker self-assembled agglomerates and creating a network that interconnects the base of the pillars, as portrayed in Fig. 7d. On the contrary, the more constrained geometry between tightly packed pillars does not allow for such enhanced interactions, and consequently, shorter agglomerates are formed.

Further agglomerates may be created above the pillar structures. Upon evaporation, in the case of large pillar spacings, agglomerates may deposit or become trapped in between the pillars, with no degree of advective flow towards the contact line able to displace them. Conversely, on surfaces with tightly packed pillars, agglomerates greater than the pillar spacing would not be able to flow in between the pillars and are hence freer to move above the structures, with the advective flow now able to push them further towards the contact line.

The described assembly of nanoparticles forming intricate patterns emphasises the intrinsic effects of pillar geometry and spacing on this behaviour. Looking forward, tailor-made surface patterns can be used to create a unique environment, leading to the formation of a broad range of complex assembled structures. Additionally, we must not overlook the importance of concentration in creating a significantly different localised particle environment between pillars, with the attain- 
ment of self-assembly only above a certain concentration. Harnessing these properties for the assembly of nano-materials via evaporative deposition shows great potential for technological advancement of specialised devices in the fields of microfabrication and nanotechnology.

\section{Conclusion}

In conclusion, we have assimilated shape selection of droplets with the coffee-ring phenomenon of particle-laden solutions on micropatterned surfaces exhibiting different shapes and population densities of surface structures. We demonstrate the behaviour of pure liquids on said substrates, before focusing on the complex drying process of aluminium oxide nanofluids at three different concentrations. The pillar-to-pillar spacing proves to be instrumental in controlling the wetting footprint, with a loss of circularity on surfaces with a high pillar density. We also compare the ability of pillar shape to induce a change in the initial wetting interface, by examining surfaces populated with circular, square, star-shaped and triangular pillars. Our focus then shifts to the drying patterns of $\mathrm{Al}_{2} \mathrm{O}_{3}$ nanofluids, where we display the overall deposition environment as well as homing in on the specifics of localised particle ordering on the microscale through the aid of microscopy. The morphology of the drying patterns was found to be significantly affected by the concentration of $\mathrm{Al}_{2} \mathrm{O}_{3}$ nanoparticles. At a lower concentration, particles deposit extensively at the vicinity of the contact line, whilst a more homogeneous deposition profile is obtained for a higher concentration due to the strengthening of the particle-particle interactions. From these results, an unusual self-assembly pattern emerges for the highest concentration, yielding complex branch-like structures between the micropillars. We hope that our findings can pave the way for the promising future of printing nanoparticle assembly in fundamental research, as well as various engineering processes.

\section{Acknowledgment}

Author Veronika Kubyshkina thanks EPSRC for supporting this research through a DPT scholarship (EP/N011341/1). The authors would like to acknowledge the support of the European space Agency (ESA), through grant Convection and Interfacial Mass Ex- change (EVAPORATION) ESA Contract Number 4000129506/20/NL/PG.

Open Access This article is licensed under a Creative Commons Attribution 4.0 International License, which permits use, sharing, adaptation, distribution and reproduction in any medium or format, as long as you give appropriate credit to the original author(s) and the source, provide a link to the Creative Commons licence, and indicate if changes were made.

The images or other third party material in this article are included in the article's Creative Commons licence, unless indicated otherwise in a credit line to the material. If material is not included in the article's Creative Commons licence and your intended use is not permitted by statutory regulation or exceeds the permitted use, you will need to obtain permission directly from the copyright holder.

To view a copy of this licence, visit http://creativecommons.org/licenses/by/4.0/.

\section{References}

[1] Calvert P. Inkjet printing for materials and devices. Chemistry of Materials, 2001, 13, 3299-3305.

[2] de Gans B J, Schubert U S. Inkjet printing of well-defined polymer dots and arrays. Langmuir, 2004, 20, 7789-7793.

[3] Yoshino M, Matsumura T, Umehara N, Akagami Y, Aravindan S, Ohno T. Engineering surface and development of a new DNA micro array chip. Wear, 2006, 260, 274-286.

[4] Bico J, Thiele U, Quéré D. Wetting of textured surfaces. Colloids and Surfaces A: Physicochemical and Engineering Aspects, 2002, 206, 41-46.

[5] Quéré D. Rough ideas on wetting. Physica A: Statistical Mechanics and Its Applications, 2002, 313, 32-46.

[6] Zhang W B, Zhu Y Z, Liu X, Wang D, Li J Y, Jiang L, Jin J. Salt-induced fabrication of superhydrophilic and underwater superoleophobic PAA-g-PVDF membranes for effective separation of oil-in-water emulsions. Angewandte Chemie International Edition, 2014, 53, 856-860.

[7] Chu K H, Enright R, Wang E N. Structured surfaces for enhanced pool boiling heat transfer. Applied Physics Letters, 2012, 100, 241603.

[8] Bico J. Pearl drops. EPL (Europhysics Letters), 1999, 47, 220-226.

[9] Ralf B. Self-cleaning surfaces - Virtual realities. Nature Materials, 2003, 2, 301-306.

[10] Cao L L, Jones A K, Sikka V K, Wu J Z, Gao D. Anti-icing 
superhydrophobic coatings. Langmuir, 2009, 25, 12444-12448.

[11] Mattaparthi S, Sharma C S. Fabrication of self-cleaning antireflective polymer surfaces by mimicking underside leaf hierarchical surface structures. Journal of Bionic Engineering, 2019, 16, 400-409.

[12] Sun Y H, Guo Z G. Recent advances of bioinspired functional materials with specific wettability: From nature and beyond nature. Nanoscale Horizons, 2019, 4, 52-76.

[13] Orejon D, Askounis A, Takata Y, Attinger D. Dropwise condensation on multiscale bioinspired metallic surfaces with nanofeatures. ACS Applied Materials \& Interfaces, 2019, 11, 24735-24750.

[14] Sharma V, Orejon D, Takata Y, Krishnan V, Harish S. Gladiolus dalenii based bioinspired structured surface via soft lithography and its application in water vapor condensation and fog harvesting. ACS Sustainable Chemistry \& Engineering, 2018, 6, 6981-6993.

[15] Chu K H, Xiao R, Wang E N. Uni-directional liquid spreading on asymmetric nanostructured surfaces. Nature Materials, 2010, 9, 413-417.

[16] Liu M J, Li J, Zhou X F, Li J Q, Feng S L, Cheng Y Q, Wang $\mathrm{S}$, Wang $\mathrm{Z} \mathrm{K}$. Inhibiting random droplet motion on hot surfaces by engineering symmetry - Breaking Janus - Mushroom structure. Advanced Materials, 2020, 32, 1907999.

[17] Sun G, Fang Y, Cong Q, Ren L Q. Anisotropism of the non-smooth surface of butterfly wing. Journal of Bionic Engineering, 2009, 6, 71-76.

[18] Jokinen V, Sainiemi L, Franssila S. Complex droplets on chemically modified silicon nanograss. Advanced Materials, 2008, 20, 3453-3456.

[19] Jokinen V, Leinikka M, Franssila S. Microstructured surfaces for directional wetting. Advanced Materials, 2009, 21, 4835-4838.

[20] Yunusa M, Ozturk F E, Yildirim A, Tuvshindorj U, Kanik M, Bayindir M. Bio-inspired hierarchically structured polymer fibers for anisotropic non-wetting surfaces. RSC Advances, 2017, 7, 15553-15560.

[21] Li X Y, Mao L Q, Ma X H. Dynamic behavior of water droplet impact on microtextured surfaces: The effect of geometrical parameters on anisotropic wetting and the maximum spreading diameter. Langmuir, 2013, 29, $1129-1138$.

[22] Vrancken R J, Blow M L, Kusumaatmaja H, Hermans K, Prenen A M, Bastiaansen C W M, Broer D J, Yeomans J M. Anisotropic wetting and de-wetting of drops on substrates patterned with polygonal posts. Soft Matter, 2013, 9,
674-683.

[23] Barbulovic-Nad I, Lucente M, Sun Y, Zhang M J, Wheeler A R, Bussmann M. Bio-microarray fabrication techniques - A review. Critical Reviews in Biotechnology, 2006, 26, 237-259.

[24] Park B K, Kim D, Jeong S, Moon J, Kim J S. Direct writing of copper conductive patterns by ink-jet printing. Thin Solid Films, 2007, 515, 7706-7711.

[25] Raj R, Adera S, Enright R, Wang E N. High-resolution liquid patterns via three-dimensional droplet shape control. Nature Communications, 2014, 5, 4975.

[26] Kumar A, Raj R. Droplets on microdecorated surfaces: Evolution of the polygonal contact line. Langmuir, 2017, 33, 4854-4862.

[27] Courbin L, Denieul E, Dressaire E, Roper M, Ajdari A, Stone H A. Imbibition by polygonal spreading on microdecorated surfaces. Nature Materials, 2007, 6, 661-664.

[28] Courbin L, Bird J C, Reyssat M, Stone H A. Dynamics of wetting: From inertial spreading to viscous imbibition. Journal of Physics: Condensed Matter, 2009, 21, 46.

[29] Feng H C, Chong K S L, Ong K S, Duan F. Octagon to square wetting area transition of water-ethanol droplets on a micropyramid substrate by increasing ethanol concentration. Langmuir, 2017, 33, 1147-1154.

[30] Zhong X, Ren J H, Lin M F, Chong K S L, Ong K S, Duan F. Octagonal wetting interface evolution of evaporating saline droplets on a micropyramid patterned surface. ACS Applied Materials \& Interfaces, 2017, 9, 28055-28063.

[31] Zhong X, Ren J H, Chong K S L, Ong K S, Duan F. Controlling octagon-to-square wetting interface transition of evaporating sessile droplet through surfactant on microtextured surface. ACS Applied Materials \& Interfaces, 2018, 10, $11425-11429$.

[32] Zhong X, Ren J C, Chong K S L, Ong K S, Duan F. Wetting transition at a threshold surfactant concentration of evaporating sessile droplets on a patterned surface. Langmuir, 2019, 35, 4509-4517.

[33] Mihi A, Zhang C, Braun P V. Transfer of preformed three-dimensional photonic crystals onto dye-sensitized solar cells. Angewandte Chemie International Edition, 2011, 50, 5712-5715.

[34] Xu X L, Goponenko A V, Asher S A. Polymerized PolyHEMA photonic crystals: $\mathrm{pH}$ and ethanol sensor materials. Journal of the American Chemical Society, 2008, 130, 3113-3119.

[35] Deegan R D, Bakajin O, Dupont T F, Huber G, Nagel S R, Witten $\mathrm{T}$ A. Capillary flow as the cause of ring stains from 
dried liquid drops. Nature, 1997, 389, 827-829.

[36] Sefiane K. On the formation of regular patterns from drying droplets and their potential use for bio-medical applications. Journal of Bionic Engineering, 2010, 7, S82-S93.

[37] Orejon D, Sefiane K, Shanahan M E R. Stick-slip of evaporating droplets: Substrate hydrophobicity and nanoparticle concentration. Langmuir, 2011, 27, 12834-12843.

[38] Bhuiyan M H U, Saidur R, Amalina M A, Mostafizur R M, Islam A. Effect of nanoparticles concentration and their sizes on surface tension of nanofluids. Procedia Engineering, 2015, 105, 431-437.

[39] Choi Y, Han J, Kim C. Pattern formation in drying of particle-laden sessile drops of polymer solutions on solid substrates. Korean Journal of Chemical Engineering, 2011, 28, 2130-2136.

[40] Yunker P J, Still T, Lohr M A, Yodh A. Suppression of the coffee-ring effect by shape-dependent capillary interactions. Nature, 2011, 476, 308-311.

[41] Larson R G. Re-shaping the coffee ring. Angewandte Chemie International Edition, 2012, 51, 2546-2548.

[42] Choi S, Stassi S, Pisano A P, Zohdi T I. Coffee-ring effect-based three dimensional patterning of micro/nanoparticle assembly with a single droplet. Langmuir, 2010, 26, 11690-11698.

[43] He A, Yang H, Xue W, Sun K, Cao Y. Tunable coffee-ring effect on a superhydrophobic surface. Optics Letters, 2017, 42, 3936-3939.

[44] Sáenz P J, Wray A W, Che Z, Matar O K, Valluri P, Kim J, Sefiane K. Dynamics and universal scaling law in geometrically-controlled sessile drop evaporation. Nature Communications, 2017, 8, 14783.

[45] Susarrey-Arce A, Marin A, Massey A, Oknianska A, Díaz-Fernandez Y, Hernández-Sánchez J F, Griffiths E, Gardeniers J G E, Snoeijer J H, Lohse D, Raval R. Pattern formation by staphylococcus epidermidis via droplet evaporation on micropillars arrays at a surface. Langmuir, 2016, 32, 7159-7169.

[46] Park H K, Kim Y, Min H, Pang C, Weon B M. Hexagonal deposits of colloidal particles. Physical Review E, 2019, 100, 022602 .

[47] Dicuangco M, Dash S, Weibel J A, Garimella S V. Effect of superhydrophobic surface morphology on evaporative deposition patterns. Applied Physics Letters, 2014, 104, 201604.

[48] Xu W, Leeladhar R, Tsai Y T, Yang E H, Choi C H. Evaporative self-assembly of nanowires on superhydrophobic surfaces of nanotip latching structures. Applied Physics
Letters, 2011, 98, 073101.

[49] Cui L Y, Zhang J H, Zhang X M, Li Y F, Wang Z H, Gao H N, Wang T Q, Zhu S J, Yu H L, Yang B. Avoiding coffee ring structure based on hydrophobic silicon pillar arrays during single-drop evaporation. Soft Matter, 2012, 8, 10448-10456.

[50] Fan F Q, Stebe K J. Assembly of colloidal particles by evaporation on surfaces with patterned hydrophobicity. Langmuir, 2004, 20, 3062-3067.

[51] Marín Á G, Gelderblom H, Susarrey-Arce A, van Houselt A, Lefferts L, Gardeniers J G, Lohse D, Snoeijer J H. Building microscopic soccer balls with evaporating colloidal fakir drops. Proceedings of the National Academy of Sciences, 2012, 109, 16455-16458.

[52] Blow M L, Kusumaatmaja H, Yeomans J M. Imbibition through an array of triangular posts. Journal of Physics: Condensed Matter, 2009, 21, 464125.

[53] Blow M L, Yeomans J M. Anisotropic imbibition on surfaces patterned with polygonal posts. Philosophical Transactions of the Royal Society A: Mathematical, Physical and Engineering Sciences, 2011, 369, 2519-2527.

[54] Wang Z L, Lin K, Zhao Y P. The effect of sharp solid edges on the droplet wettability. Journal of Colloid and Interface Science, 2019, 552, 563-571.

[55] Chauvet F, Duru P, Prat M. Depinning of evaporating liquid films in square capillary tubes: Influence of corners' roundedness. Physics of Fluids, 2010, 22, 112113.

[56] Wong T S, Chen T H, Shen X Y, Ho C M. Nanochromatography driven by the coffee ring effect. Analytical Chemistry, 2011, 83, 1871-1873.

[57] Wen J T, Ho C M, Lillehoj P B. Coffee ring aptasensor for rapid protein detection. Langmuir, 2013, 29, 8440-8446.

[58] Gulka C P, Swartz J D, Trantum J R, Davis K M, Peak C M, Denton A J, Haselton F R, Wright D W. Coffee rings as low-resource diagnostics: Detection of the malaria biomarker plasmodium falciparum histidine-rich protein-ii using a surface-coupled ring of Ni (II) NTA gold-plated polystyrene particles. ACS Applied Materials \& Interfaces, 2014, 6, 6257-6263.

[59] Lin Z Q. Controlled evaporative assembly of polymers from confined solutions. Journal of Polymer Science Part B: Polymer Physics, 2010, 48, 2552-2557.

[60] Salem A K, Rose F R, Oreffo R O, Yang X, Davies M C, Mitchell J R, Roberts C J, Stolnik-Trenkic S, Tendler S J, Williams P M, Shakesheff K M. Porous polymer and cell composites that self-assemble in situ. Advanced Materials, 2003, 15, 210-213.

[61] Maul T, Bargiela, A, Yan Y Y, Gao N, Foss A. Simulation 
modelling study of self-assembled nanoparticle coatings for retinal implants. Journal of Bionic Engineering, 2013, 10, 65-76.

[62] Lee S J J. Microfabrication for Microfluidics. Artech House, Boston, USA, 2010.

[63] de Gennes P G, Brochard-Wyart F, Quéré D. Capillarity and Wetting Phenomena. Springer, New York, USA, 2004.

[64] Tanvir S, Qiao L. Surface tension of nanofluid-type fuels containing suspended nanomaterials. Nanoscale Research Letters, 2012, 7, 226.

[65] Weon B M, Je J H. Self-pinning by colloids confined at a contact line. Physical Review Letters, 2013, 110, 028303.

[66] Lee H H, Fu S C, Tso C Y, Chao C Y H. Study of residue patterns of aqueous nanofluid droplets with different particle sizes and concentrations on different substrates. International Journal of Heat and Mass Transfer, 2017, 105, 230-236.

[67] Jing G Y, Ma J. Formation of circular crack pattern in deposition self-assembled by drying nanoparticle suspension. The Journal of Physical Chemistry B, 2012, 116, $6225-6231$

[68] Brutin D. Influence of relative humidity and nano-particle concentration on pattern formation and evaporation rate of pinned drying drops of nanofluids. Colloids and Surfaces A: Physicochemical and Engineering Aspects, 2013, 429, $112-120$

[69] Askounis A, Orejon D, Koutsos V, Sefiane K, Shanahan M E R. Nanoparticle deposits near the contact line of pinned volatile droplets: Size and shape revealed by atomic force microscopy. Soft Matter, 2011, 7, 4152-4155.

[70] Hemalatha J, Prabhakaran T, Pratibha Nalini R. A comparative study on particle-fluid interactions in micro and nanofluids of aluminium oxide. Microfluidics and Nanofluidics, 2011, 10, 263-270.

[71] Dugyala V R, Basavaraj M G. Control over coffee-ring formation in evaporating liquid drops containing ellipsoids. Langmuir, 2014, 30, 8680-8686.

[72] Crivoi A, Zhong X, Duan F. Crossover from the coffee-ring effect to the uniform deposit caused by irreversible cluster-cluster aggregation. Physical Review E, 2015, 92, 032302.

[73] Li Y N, Yang Q, Li M Z, Song Y L. Rate-dependent interface capture beyond the coffee-ring effect. Scientific Reports, 2016, 6, 27963. 